\title{
Molecular Structure and Electronic Properties of Porphyrin-Thiophene-Perylene Using Quantum Chemical Calculation
}

\author{
Tatiya Chokbunpiam, ${ }^{1,2}$ Patchanita Thamyongkit, ${ }^{3}$ Oraphan Saengsawang, ${ }^{2}$ \\ and Supot Hannongbua ${ }^{2,4}$ \\ ${ }^{1}$ Petrochemical and Polymer Science Program, Faculty of Science, Chulalongkorn University, Bangkok 10330, Thailand \\ ${ }^{2}$ Computational Chemistry Unit Cell (CCUC), Department of Chemistry, Faculty of Science, Chulalongkorn University, \\ Bangkok 10330, Thailand \\ ${ }^{3}$ Department of Chemistry, Faculty of Science, Chulalongkorn University, Bangkok 10330, Thailand \\ ${ }^{4}$ Center of Excellence for Petroleum, Petrochemical, and Advanced Materials, Chulalongkorn University, Bangkok 10330, Thailand
}

Correspondence should be addressed to Supot Hannongbua, supot.h@chula.ac.th

Received 20 April 2010; Accepted 20 September 2010

Academic Editor: David Lee Phillips

Copyright ( $\odot 2010$ Tatiya Chokbunpiam et al. This is an open access article distributed under the Creative Commons Attribution License, which permits unrestricted use, distribution, and reproduction in any medium, provided the original work is properly cited.

\begin{abstract}
This study aimed to design a new series of compounds consisting of a porphyrin macrocycle linked to a perylene unit via a thiophenic bridge. The structural and electronic properties of the molecules, and the effects of mono- and di-substituents $\mathrm{R}$ on $\mathrm{C}_{3}$ and $\mathrm{R}^{\prime}$ on $\mathrm{C}_{4}$ of the thiophene ring were investigated using a quantum calculation approach. The results from the method validation revealed that using the density functional theory approach at B3LYP/6-31G(d) data set was the optimal one, considering the accuracy attained and maintaining the computer time required within tractable limits. The results from the B3LYP/6-31G(d) approach indicated that significant changes of the torsion angle between the molecular planes of the porphyrin and perylene rings, compared to that of the unsubstituted derivatives, were found in the di-substituted systems bearing $\mathrm{R}=\mathrm{R}^{\prime}=-\mathrm{OCH}_{3}$ and $-\mathrm{NH}_{2}$, and in a mono-substituted system having $\mathrm{R}=-\mathrm{H}$ and $\mathrm{R}^{\prime}=-\mathrm{NH}_{2}$. The symmetric di-substitution does not provide a significantly lower HOMO-LUMO energy gap $(\Delta E g)$. Noticeable decreases in $\Delta E g$ were found only with the substitution patterns of: $\mathrm{R}, \mathrm{R}^{\prime}$ $=-\mathrm{OCH}_{3},-\mathrm{H} ;-\mathrm{OH},-\mathrm{H} ;-\mathrm{N}\left(\mathrm{CH}_{3}\right)_{2},-\mathrm{H} ;-\mathrm{H},-\mathrm{NH}_{2}$. UV-visible spectra of all derivatives exhibited characteristic absorption maxima of the free bases of porphyrin and perylene.
\end{abstract}

\section{Introduction}

Since the present cost of electricity from silicon-based photovoltaics (PVs) is significantly higher than the current commercial prices of electricity generated by hydraulic power, nuclear and fossil fuels, it is necessary to develop low-cost solar cells with a high power conversion efficiency (PCE). As promising candidates organic-based solar cells have increasingly attracted the attention of scientists. One of the key developments of organic compounds for solar cells comes from the molecular design allowing photophysical, electrochemical, and optical properties of the molecules to be tune. This becomes the main propose of this study which focuses on the design of a new series of compounds con- sisting of a porphyrin macrocycle linked to a perylene unit via a thiophenic bridge that exhibits an extended absorption range, a narrow band gap, and potential electronic transfer, by using quantum chemical calculation.

After the first pioneered fabrication of dye-sensitized organic-based solar cells [1], solar cell researchers have put their best effort to understand the device function in order to achieve improvements in the somewhat poor light harvesting efficiency, and thus the feasibility, of this type of device for commercial purposes. Pigments related to the chlorophylls, such as porphyrins, are particularly promising light absorbers for solar cell applications, owing to their large molar absorption coefficients, tuneable photophysical properties, and amenability to molecular modification. 


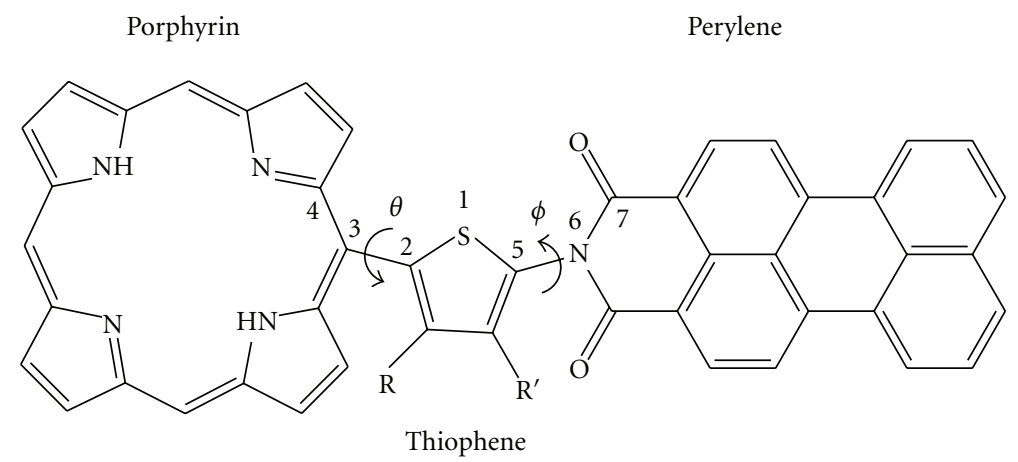

Figure 1: Two-dimensional structure of the PTP sensitizer compound $\left(\mathrm{R}=\mathrm{R}^{\prime}=-\mathrm{H}\right)$ and its derivatives where $(\mathrm{i}) \mathrm{R}=-\mathrm{H}$, and $\mathrm{R}^{\prime}=-\mathrm{H}$, $-\mathrm{CH}_{3},-\mathrm{OCH}_{3},-\mathrm{OH},-\mathrm{NH}_{2},-\mathrm{N}\left(\mathrm{CH}_{3}\right)_{2},-\mathrm{CN}$, or $-\mathrm{NO}_{2}$; (ii) $\mathrm{R}=-\mathrm{H},-\mathrm{CH}_{3},-\mathrm{OCH}_{3},-\mathrm{OH},-\mathrm{NH}_{2},-\mathrm{N}(\mathrm{CH} 3)_{2},-\mathrm{CN}$, or $-\mathrm{NO}_{2}$; and $\mathrm{R}^{\prime}=-\mathrm{H}$; (iii) $\mathrm{R}=\mathrm{R}^{\prime}=-\mathrm{H},-\mathrm{CH}_{3},-\mathrm{OCH}_{3},-\mathrm{OH},-\mathrm{NH}_{2},-\mathrm{N}\left(\mathrm{CH}_{3}\right)_{2},-\mathrm{CN}$, or $-\mathrm{NO}_{2}$. The torsion angles, $\theta$ and $\phi$, were defined by 1-2-3-4 and 1-5-6-7, respectively.

Nevertheless, porphyrins effectively adsorb in the near UV region which, however, is a rather small fraction of the total available solar photons. One of the popular approaches for the molecular design of organic light harvesters is utilizing structurally related chromophores that absorb strongly in the trough between the porphyrin Soret (B) and Q-bands. Highly suitable chromophore for this requirement, that are taken into consideration in this study, is perylene. The use of perylene as an accessory pigment in the porphyrin system is attractive for light-harvesting applications due to the high near-infrared absorption coefficient, the rapid and efficient energy transfer, and the satisfactorily long lifetime of the resulting molecules $[2,3]$.

Since a good understanding of the electronic properties, such as a energy gap and a frontier orbital levels, is a key factor to design a new and appropriate structure for organic dye and, hence, to increase the efficiency of the solar cells, the goal of this work is to theoretically predict such structural and electronic properties of a novel porphyrinperylene dyad bridged by a 2,5-thiophenylene linker using quantum chemical calculation. Incorporation of the thiophene moiety in several previously studied binuclear systems afforded effective intermolecular electronic communication [4-6]. In this paper, we firstly focused on the structural optimization in terms of the intermolecular torsion angle using a simple B3LYP/6-31G(d) method. After that, the calculation outcome in terms of HOMO and LUMO levels, energy gap, and CPU time resulted from the same density function theory approach (B3LYP) with four different sizes of basis sets were compared to seek the method of choice for further studies concerning the effect of various substituents at the 3 and/or 4 positions of the thiophene linker on the structural and electronic properties, and for the computational investigation of absorption spectra of these derivatives. The approach is general and could be useful for studying other systems containing other organic photo sensitizers.

\section{Computational Methods}

2.1. Optimal Structure of the Porphyrin-Thiophene-Perylene (PTP) Sensitizer Compound. The initial structure of the porphyrin-thiophene-perylene $(\mathrm{PTP})$ compound, where $\mathrm{R}=$ $\mathrm{R}^{\prime}=-\mathrm{H}$, was generated using the GaussView program and is shown in Figure 1. Since it has been successfully used in the previous studies [7-14], the density functional theory (DFT) approach at the B3LYP/6-31G(d) basis set was used in this study to search for the optimal structure of the investigated compound. Here, two procedures were separately applied, (i) the structure was fully optimized, that is, all atoms were allowed to relax and (ii) to examine whether the obtained structure is the global minimum energy conformation, two torsion angles, $\theta$ and $\phi$, shown in Figure 1, were defined.

The geometries, bond lengths, and bond angles obtained from (i) were kept constant throughout, whereas the torsion angles were optimized in the following manner. The angle $\theta$ was fixed at $0^{\circ}$ whilst $\phi$ was scanned from $0^{\circ}$ to $180^{\circ}$ in $30^{\circ}$ intervals. This procedure was then repeated, varying $\phi$ as above whilst keeping $\theta$ at $30^{\circ}, 60^{\circ}, 90^{\circ}, 120^{\circ}, 150^{\circ}$, and $180^{\circ}$ in turn, respectively. In order to get more precise conformation, this procedure was repeated in the range around the optimal $\theta$ but with $\phi$ angles varied in intervals of $5^{\circ}$ and then $2^{\circ}$. All calculations were performed using the Gaussian 03 program package [15].

2.2. Optimal Structure of PTP Derivatives. Interest was focused on the derivatives with the following electron donating $\left(-\mathrm{CH}_{3},-\mathrm{OCH}_{3},-\mathrm{OH},-\mathrm{NH}_{2}\right.$ and $\left.-\mathrm{N}\left(\mathrm{CH}_{3}\right)_{2}\right)$, and electron withdrawing $\left(-\mathrm{CN}\right.$ and $\left.-\mathrm{NO}_{2}\right)$, groups. Starting from the optimal structure of the PTP compound, where R $=\mathrm{R}^{\prime}=-\mathrm{H}$, the following substitution-based PTP derivatives were built: (i) $\mathrm{R}=-\mathrm{H}$, and $\mathrm{R}^{\prime}=-\mathrm{CH}_{3},-\mathrm{OCH}_{3},-\mathrm{OH},-\mathrm{NH}_{2}$, $-\mathrm{N}\left(\mathrm{CH}_{3}\right)_{2},-\mathrm{CN}$, or $-\mathrm{NO}_{2}$; (ii) $\mathrm{R}=-\mathrm{CH}_{3},-\mathrm{OCH}_{3}-\mathrm{OH},-$ $\mathrm{NH}_{2},-\mathrm{N}\left(\mathrm{CH}_{3}\right)_{2},-\mathrm{CN}$, or $-\mathrm{NO}_{2}$, and $\mathrm{R}^{\prime}=-\mathrm{H}$; and (iii) $\mathrm{R}$ $=\mathrm{R}^{\prime}=-\mathrm{CH}_{3},-\mathrm{OCH}_{3},-\mathrm{OH},-\mathrm{NH}_{2},-\mathrm{N}\left(\mathrm{CH}_{3}\right)_{2},-\mathrm{CN}$, or $\mathrm{NO}_{2}$. Note that the derivatives, where $\mathrm{R} \neq \mathrm{R}^{\prime}$, are not taken into account for two reasons. Firstly, to simplify the data interpretation and, secondly, because asymmetric substitution on the thiophene ring is synthetically complicated to be achieved and so would not likely be economically practical for the commercial-scale manufacture of such solar cells. To search for the most stable structure of these compounds, two steps of partial optimization were applied. Firstly, only 
the geometries of the substituted groups (whilst those of the other atoms were taken from the results of Section 2.1 above and kept constant throughout) were fully optimized. Secondly, the obtained geometries were fixed and the two torsion angles $(\theta$ and $\phi)$ were adjusted in order to seek the preferential conformation of the derivatives.

2.3. Optimal Method for the Electronic Property Investigations. With the optimal structure of the PTP compound and its derivatives obtained from the analysis in Sections 2.1 and 2.2 above, the B3LYP calculations with the four different basis sets, 6-31G(d), 6-31G(d,p), 6-31G+(d), and 6-31G+(d,p), were performed. Seeking for a compromise between the accuracy and the required computer time, the electronic properties of the calculated systems were used to validate the method applied. The resulting optimal method was then used for the investigation of the electronic properties of the molecule of interest throughout.

\section{Results and Discussions}

3.1. Optimal Structure of the PTP Compound. Using the full optimization procedure and the B3LYP/6-31G(d) method, outlined under methods above, the calculated structure of the PTP compound, where $\mathrm{R}=\mathrm{R}^{\prime}=-\mathrm{H}$, takes place at the torsion angles $\theta$ and $\phi$ of $109^{\circ}$ and $80^{\circ}$, respectively (Figure 2).

In another approach, the potential energy surfaces, where $\theta$ and $\phi$ were optimized manually at the angle intervals $30^{\circ}, 5^{\circ}$, and $2^{\circ}$, were shown in Figures $3(\mathrm{a}), 3(\mathrm{~b})$, and $3(\mathrm{c})$, respectively. As shown in Figure 3(c), the calculated energy minimum lies in the ranges $106^{\circ}-110^{\circ}$ for $\theta$ and $80^{\circ}-84^{\circ}$ for $\phi$. Good agreement between the results yielded from the two optimized procedures indicates reliability of the obtained structure.

3.2. Optimal Method for the Electronic Properties Investigations. With the optimal configuration of the PTP $\left(\mathrm{R}=\mathrm{R}^{\prime}=\right.$ $-\mathrm{H}$ ) compound evaluated as $\theta=109^{\circ}$ and $\phi=80^{\circ}$, the B3LYP method with four different sizes of basis sets was applied to examine the electronic properties of the investigated compound, taken into account not only the optimal level of accuracy, but also the compromise between the reliability of the calculated results and the CPU (Computation Processing Units) time needed. The derived HOMO, LUMO, and energy gap, as well as the required CPU times, are summarized in Table 1. Examinations were also extended to the PTP and its derivatives, where $\mathrm{R}=\mathrm{R}^{\prime}=-\mathrm{OCH}_{3},-\mathrm{OH},-\mathrm{CN}$, or $-\mathrm{NO}_{2}$, and the results are compared in Figure 4.

As can clearly be seen from the data in Table 1 , significant differences of the HOMO and LUMO energies were yielded when the diffusion functions, $6-31 \mathrm{G}+(\mathrm{d})$ and $6-31 \mathrm{G}+(\mathrm{d}, \mathrm{p})$, were included. As expected, the absolute energies were found not to effect the HOMO-LUMO energy gap significantly, being $2.162,2.160,2.115$, and $2.114 \mathrm{eV}$ for the $6-31 \mathrm{G}(\mathrm{d})$ and $6-31 \mathrm{G}(\mathrm{d}, \mathrm{p}), 6-31 \mathrm{G}+(\mathrm{d})$ and $6-31 \mathrm{G}+(\mathrm{d}, \mathrm{p})$ basis sets, respectively. These conclusions were also true for the selected PTP derivatives, where the energy data are shown in Figure 4 . To attain the same level of accuracy for all four derivatives defined in Figure 1, the CPU time required to

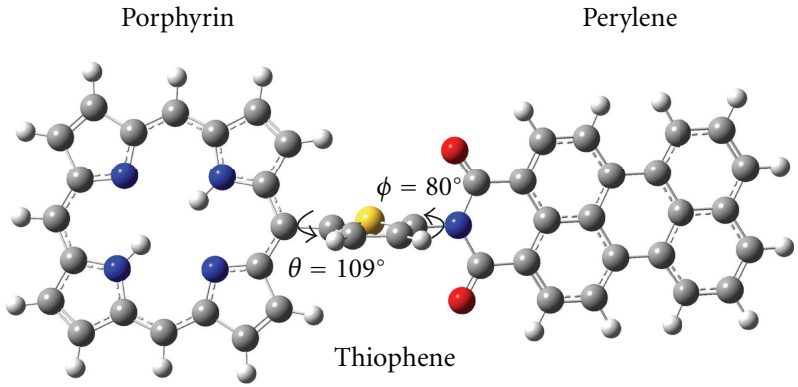

FIgURE 2: The optimal structure of the PTP compound $\left(\mathrm{R}=\mathrm{R}^{\prime}=\right.$ $-\mathrm{H}$ ), where $\theta=109^{\circ}$ and $\phi=80^{\circ}$, obtained from the B3LYP/6$31 \mathrm{G}(\mathrm{d})$ calculation.

take into account the diffusion functions $(6-31 \mathrm{G}+(\mathrm{d})$ and $6-31 G+(d, p))$ is dramatically higher than those of the other two basis sets. Therefore, the B3LYP/6-31G(d) was chosen to be the optimal method for the calculation of the electronic properties of all the compounds in this study.

From the selected B3LYP/6-31G(d) calculation, the frontier molecular orbitals corresponding to the HOMO and LUMO energies for the most stable structure of the PTP compound, where $\mathrm{R}=\mathrm{R}^{\prime}=-\mathrm{H}$, were visualized, and the results are shown in Figure 5. The HOMO coefficient was mapped to the porphyrin unit whereas that for LUMO was found to locate on the perylene unit, that is, the porphyrin and the perylene moieties were assigned to act as the electron donor and acceptor, respectively. From the plots, electron transfer from the porphyrin moiety to that of the perylene moiety, which is the important feature for the electronic conductivity in solar cell application, was clearly visualized.

3.3. Structure and Electronic Property of the PTP Derivatives. With reference to the calculation details given in Section 2.2, the changes in the torsion angles $(\Delta \theta$ and $\Delta \phi$, defined in Figure 2), and the corresponding energy gap $(\Delta E g)$, of the PTP derivatives obtained from the B3LYP/6-31G(d) calculations, relative to those of the PTP compound $\left(\mathrm{R}=\mathrm{R}^{\prime}=\right.$ $-\mathrm{H}$ ), were extracted and are summarized in Table 2. Here, the values obtained from the PTP compounds were subtracted from those of its derivatives. Therefore, a negative value for the change of torsion angle denotes the rotation in the direction opposite to the arrow defined in Figure 2, whereas a negative $\Delta E g$ means that the newly designed derivative gives a narrower energy gap and vice versa. In addition, absolute value of the $|\Delta \phi-\Delta \theta|$ implies the change in the torsion angle between the two molecular planes of the porphyrin and perylene units.

In terms of molecular structure, it is clearly seen from Table 2 that the significant change of the torsion angle $(\mid \Delta \phi-$ $\Delta \theta \mid)$ of $>20^{\circ}$ was found in two disubstituted derivatives, where $\mathrm{R}=\mathrm{R}^{\prime}=-\mathrm{OCH}_{3}$ and $-\mathrm{NH}_{2}$, and one monosubstituted derivative, where $\mathrm{R}=-\mathrm{H}$ and $\mathrm{R}^{\prime}=-\mathrm{NH}_{2}$ (marked as bold characters in Table 2). These findings can be described in terms of interaction between thiophene subsitutents and one or both oxygen atoms of the perylene unit. Steric hindrance due to the $-\mathrm{OCH}_{3}$ substituent repulses the oxygen atom of the perylene, leading to the positive $\Delta \phi$ (perylene was 


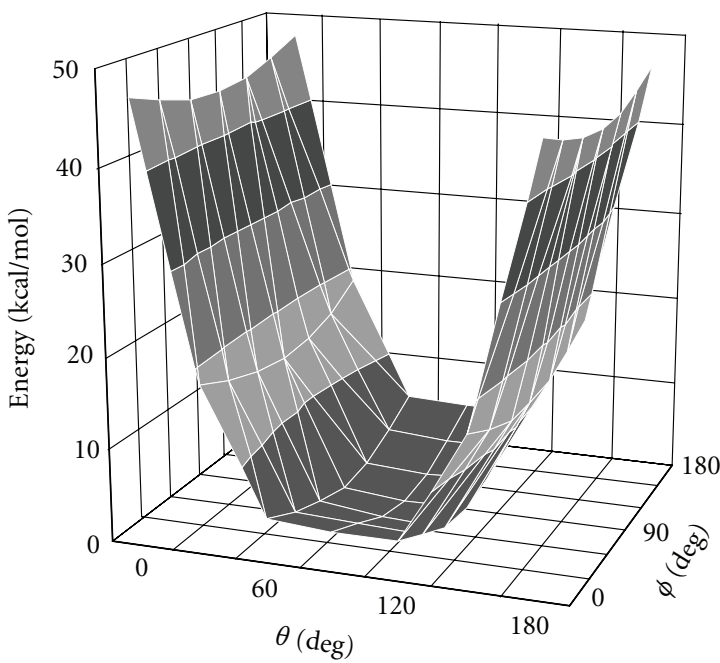

(a)

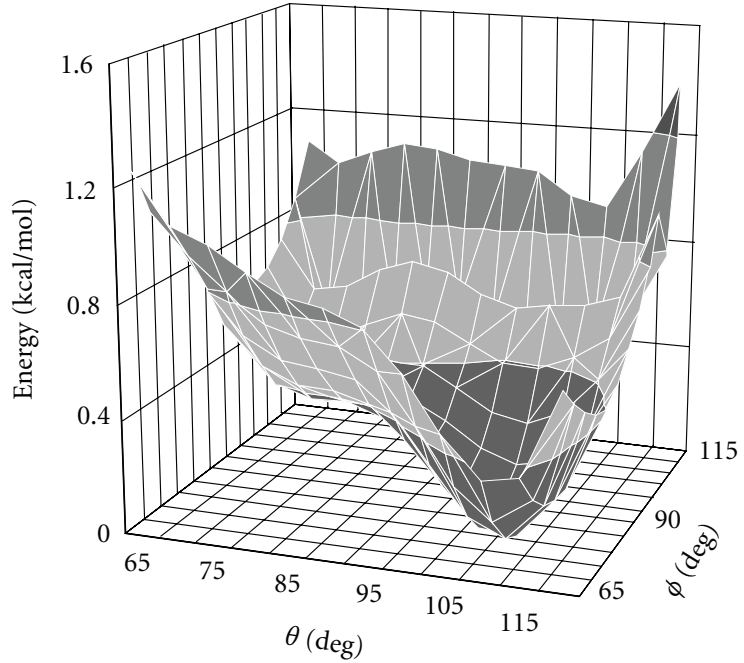

(b)

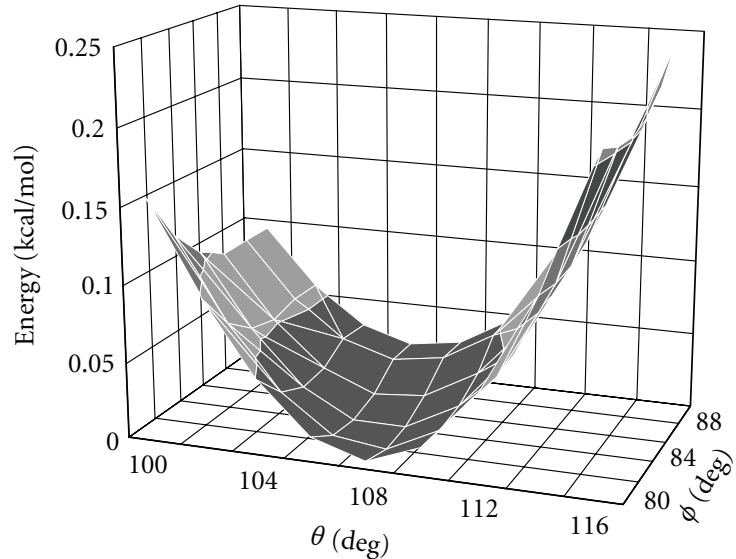

(c)

Figure 3: (a)-(c) The potential energy surfaces of the PTP sensitizer compound, where $\mathrm{R}=\mathrm{R}^{\prime}=-\mathrm{H}$, as a function of the torsion angles $(\theta$ and $\phi$ defined in Figure 2), optimized manually at the angle intervals $30^{\circ}, 5^{\circ}$, and $2^{\circ}$, respectively.

TABLE 1: HOMO, LUMO, energy gap, and CPU times yielded from the B3LYP method at different sizes of the basis sets for PTP, where R = $\mathrm{R}^{\prime}=-\mathrm{H}, \theta=109^{\circ}$, and $\phi=80^{\circ}$ (see Figure 2 for definition).

\begin{tabular}{|c|c|c|c|c|}
\hline Method & $\operatorname{HOMO}(\mathrm{eV})$ & $\mathrm{LUMO}(\mathrm{eV})$ & Energy Gap (eV) & CPU time (hr:min) \\
\hline B3LYP/6-31 G(d) & -5.030 & -2.868 & 2.162 & $0: 44$ \\
\hline B3LYP/6-31 G(d,p) & -5.040 & -2.880 & 2.160 & $0: 51$ \\
\hline B3LYP/ 6-31 G+(d) & -5.323 & -3.208 & 2.115 & $9: 42$ \\
\hline B3LYP/ 6-31 G+(d,p) & -5.334 & -3.220 & 2.114 & $10: 12$ \\
\hline
\end{tabular}

rotated in the direction of the arrow shown in Figure 2) by $20^{\circ}$. This is not the case for the $-\mathrm{N}\left(\mathrm{CH}_{3}\right)_{2}$ disubstitution in which steric repulsion between methyl groups of the amino substitutent and both perylene oxygen atoms impedes free rotation of the perylene around the $\mathrm{C}-\mathrm{N}$ bond (see also Figure 2) and tilts the angle $\phi$ by only $8^{\circ}$. For the $-\mathrm{NH}_{2}$, the perylene unit was rotated by $-19^{\circ}$ for the disubstituted case and $-16^{\circ}$ for the monosubstituted one due to a weak intramolecular hydrogen bond between $-\mathrm{NH}_{2}$ and perylene oxygen atom. This hydrogen bond could not be formed in the case of $-\mathrm{OH}$ substitution because of the repulsion between two electron-rich oxygen atoms of the $-\mathrm{OH}$ group and that of the perylene moiety.

It has been well known that the use of low-band gap materials is a viable approach to increase the light-harvesting efficiency of the solar cells. As regards the effect of the 


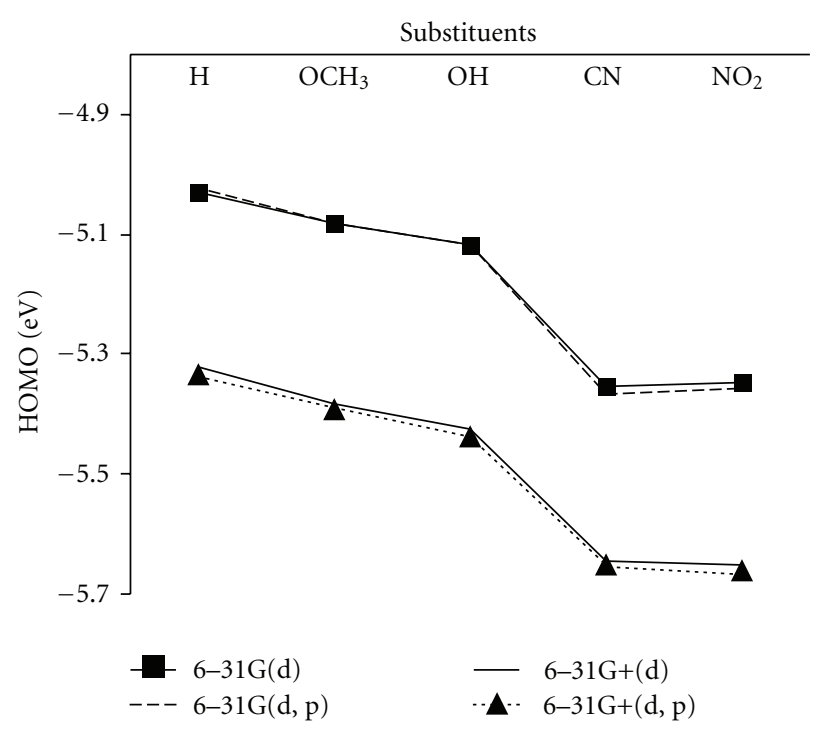

(a)

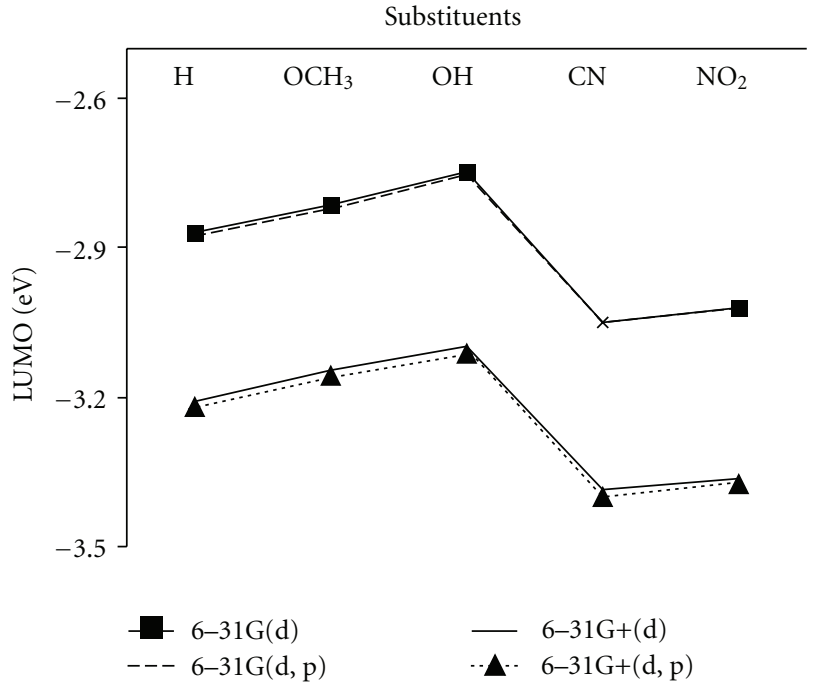

(b)

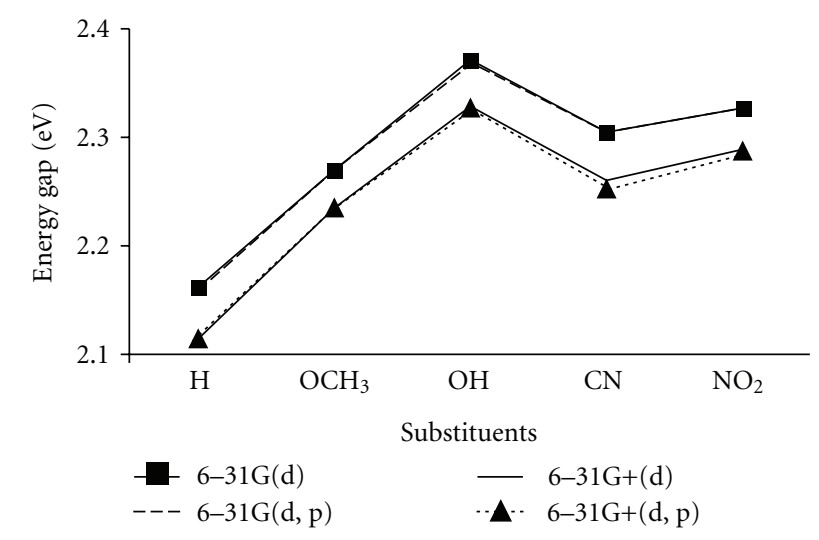

(c)

Figure 4: (a) HOMO, (b) LUMO, and (c) energy gap of the PTP compound (where $\mathrm{R}=\mathrm{R}^{\prime}=-\mathrm{H}$ ), and its derivatives (where $\mathrm{R}=\mathrm{R}^{\prime}=-\mathrm{H}$, $-\mathrm{OCH}_{3},-\mathrm{OH},-\mathrm{CN}$, and $-\mathrm{NO}_{2}$ ), calculated using the B3LYP method with different basis sets.

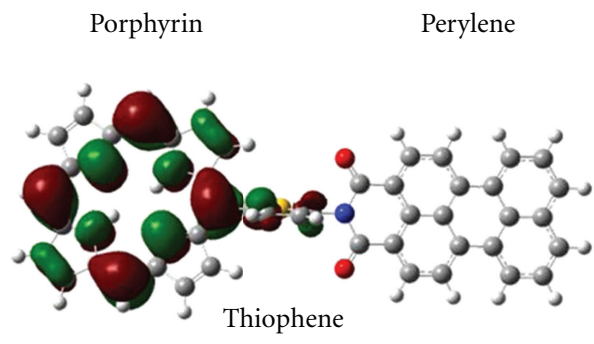

HOMO
Porphyrin Perylene

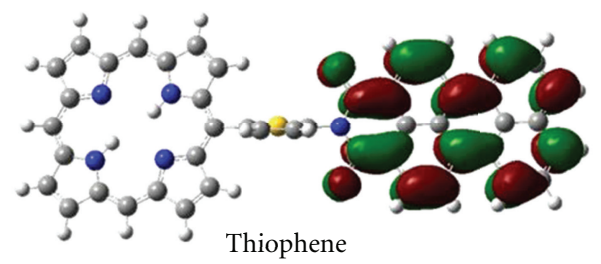

LUMO

FIGURE 5: Frontier molecular orbital of PTP visualized by TD-B3LYP/6-31G(d) calculations indicated the electron donor and electron acceptor features of the porphyrin and perylene units, respectively. 
TABLE 2: Changes of the torsion angles ( $\Delta \theta$ and $\Delta \phi$, defined in Figure 2), and the corresponding energy gap ( $\Delta E g$ ), of the PTP derivatives obtained from the B3LYP/6-31G(d) calculations, relative to those of the PTP compound $\left(\mathrm{R}=\mathrm{R}^{\prime}=-\mathrm{H}\right)$, after subtraction of the values obtained from the PTP compounds by those of its derivatives.

\begin{tabular}{|c|c|c|c|c|}
\hline \multirow{2}{*}{ Substituent R/R' } & \multicolumn{3}{|c|}{ Torsion angle (degree) } & \multirow{2}{*}{$\Delta E g(\mathrm{eV})$} \\
\hline & $\Delta \theta$ & $\Delta \phi$ & $|\Delta \phi-\Delta \theta|$ & \\
\hline \multicolumn{5}{|l|}{ Disubstituted derivative } \\
\hline $\mathrm{H}, \mathrm{H}$ & 0.0 & 0.0 & 0.0 & 0.0 \\
\hline $\mathrm{CH}_{3}, \mathrm{CH}_{3}$ & -7 & 4 & 11 & 0.019 \\
\hline $\mathrm{OCH}_{3}, \mathrm{OCH}_{3}$ & -2 & 20 & 22 & 0.108 \\
\hline $\mathrm{OH}, \mathrm{OH}$ & 5 & 5 & 0 & 0.209 \\
\hline $\mathrm{NH}_{2}, \mathrm{NH}_{2}$ & 4 & -19 & 23 & -0.089 \\
\hline $\mathrm{N}\left(\mathrm{CH}_{3}\right)_{2}, \mathrm{~N}\left(\mathrm{CH}_{3}\right)_{2}$ & -1 & 8 & 9 & -0.086 \\
\hline $\mathrm{CN}, \mathrm{CN}$ & 0 & 0 & 0 & 0.143 \\
\hline $\mathrm{NO}_{2}, \mathrm{NO}_{2}$ & -7 & 6 & 13 & 0.164 \\
\hline \multicolumn{5}{|c|}{ Monosubstituted derivative } \\
\hline $\mathrm{CH}_{3}, \mathrm{H} / \mathrm{H}, \mathrm{CH}_{3}$ & $-6 / 4$ & $3 /-7$ & $9 / 11$ & $0.045 /-0.051$ \\
\hline $\mathrm{OCH}_{3}, \mathbf{H} / \mathrm{H}, \mathrm{OCH}_{3}$ & $0 / 2$ & $1 / 5$ & $1 / 3$ & $-\mathbf{0 . 1 5 7 / 0 . 0 9 7}$ \\
\hline $\mathrm{OH}, \mathbf{H} / \mathrm{H}, \mathrm{OH}$ & $-1 / 0$ & $0 / 0$ & $1 / 0$ & $-0.157 / 0.128$ \\
\hline $\mathrm{NH}_{2}, \mathrm{H} / \mathbf{H}, \mathbf{N H}_{2}$ & $1 / 5$ & $1 /-16$ & $0 / 21$ & $-0.065 /-\mathbf{0 . 1 3 4}$ \\
\hline $\mathrm{N}\left(\mathrm{CH}_{3}\right)_{2}, \mathrm{H} / \mathrm{H}, \mathrm{N}\left(\mathrm{CH}_{3}\right)_{2}$ & $2 / 3$ & $6 / 3$ & $4 / 0$ & $-0.118 / 0.028$ \\
\hline $\mathrm{CN}, \mathrm{H} / \mathrm{H}, \mathrm{CN}$ & $-3 / 0$ & $-1 / 1$ & $2 / 1$ & $0.016 / 0.143$ \\
\hline $\mathrm{NO}_{2}, \mathrm{H} / \mathrm{H}, \mathrm{NO}_{2}$ & $-3 / 2$ & $1 / 4$ & $4 / 2$ & $-0.022 / 0.205$ \\
\hline
\end{tabular}

substitution on the HOMO-LUMO energy gap $(\Delta E g)$, the calculation results led to the following remarkable observations: (i) the symmetric disubstitution did not significantly reduce $\Delta E g$, (ii) the noticeable changes of the HOMOLUMO energy gap were found in four derivatives where $\mathrm{R}, \mathrm{R}^{\prime}$ $=-\mathrm{OCH}_{3},-\mathrm{H} ;-\mathrm{OH},-\mathrm{H} ;-\mathrm{N}\left(\mathrm{CH}_{3}\right)_{2},-\mathrm{H}$; and $-\mathrm{H},-\mathrm{NH}_{2}$ with the reduction of the $\Delta E g$ by $-0.157 \mathrm{eV},-0.157 \mathrm{eV}$, $-0.118 \mathrm{eV}$, and $-0.134 \mathrm{eV}$, respectively, (iii) a decrease in $\Delta E g$ was significant only when the substituents are electron donor groups. However, no relation was found between a degree of electron-donating strength and $\Delta E g$ reduction, and (iv) three of four derivatives mentioned in (ii), including ones having $\mathrm{R}, \mathrm{R}^{\prime}=-\mathrm{OCH}_{3},-\mathrm{H} ;-\mathrm{OH},-\mathrm{H}$; and $-\mathrm{N}\left(\mathrm{CH}_{3}\right)_{2},-\mathrm{H}$, have substitution on the thiophene ring closer to the porphyrin unit.

According to the observations in (iii) and (iv) above, it can be concluded that the substitution of the electrondonating group on the thiophene ring closer to the porphyrin unit is a more favorable choice for the design of a new photo sensitizer for solar cells. This finding can be clearly understood by the electron density distribution of the frontier molecular orbital, shown in Figure 5, where the porphyrin unit was shown to serve as the electron donor and the perylene unit as electron acceptor. Therefore, an increase in the electron density of the porphyrin unit by the substitution of an electron-donating substituent on the thiophene ring is supposed to directly facilitate the electron transfer to the perylene, a known key mechanism for light-harvesting system. However, since $-\mathrm{NH}_{2}$ substitution provided a decrease in the energy gap of $-0.134 \mathrm{eV}$ when introduced onto the thiophene ring close to the perylene unit $\left(\mathrm{R}=-\mathrm{H}\right.$ and $\mathrm{R}^{\prime}=-\mathrm{NH}_{2}$, Table 2$)$, it is likely that a faster electron transfer, compared to the unsubstituted system, can be obtained when the $-\mathrm{NH}_{2}$ group is on the thiophene ring closer to the perylene unit instead. The reason for this exceptional result can be explained by the intramolecular hydrogen bond between the amino hydrogen atom and the perylene oxygen one as described above, which possibly assisted the electron transfer from the porphyrin unit to the perylene unit.

3.4. UV-Visible Spectra of the PTP Derivatives. Using the TD-B3LYP-derived calculations in the Gaussion 03 package, the UV-visible spectra for the investigated compounds were calculated. The obtained results for the freebase porphyrin, the perylene, the PTP compound, and the four newly designed derivatives are summarized in Figure 6.

The free-base porphyrin shows a maximum absorption at $372 \mathrm{~nm}$ whereas that for the perylene was at $473 \mathrm{~nm}$ (Figures 6(a) and 6(b)), respectively. The two calculated maxima, 372 and $473 \mathrm{~nm}$, are in agreement with those yielded experimentally for the free-base porphyrin and perylene, respectively $[2,16,17]$.

Several peaks were observed for the PTP compound ( R $=\mathrm{R}^{\prime}=-\mathrm{H}$ ) and the four newly designed derivatives. It appears also that the absorption spectra of the PTP and its derivatives cover a broader range, 370-730 nm (Figures 6(c)6(g)), compared to those between $372 \mathrm{~nm}$ and $473 \mathrm{~nm}$ for the two free bases (Figures 6(a) and 6(b)). The most important feature is that the absorption characteristics of the porphyrin and perylene molecules, that is, the absorption peaks at 372 


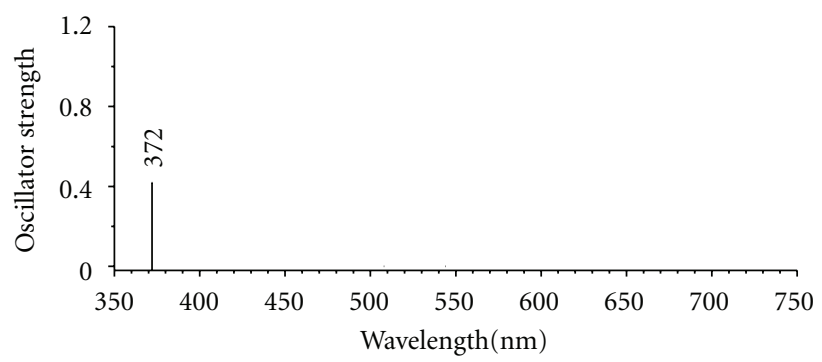

(a) Porphyrin

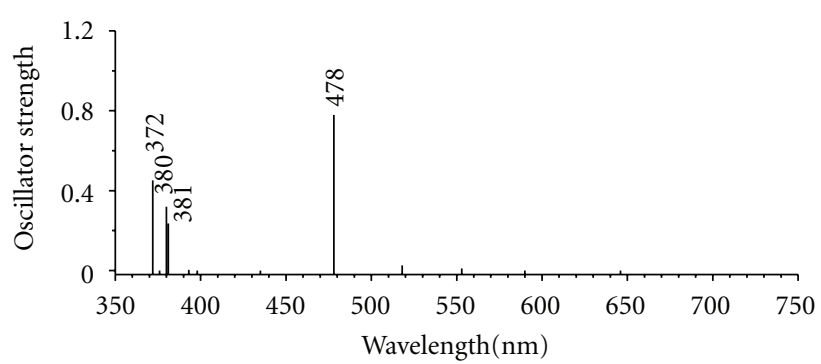

(c) PTP

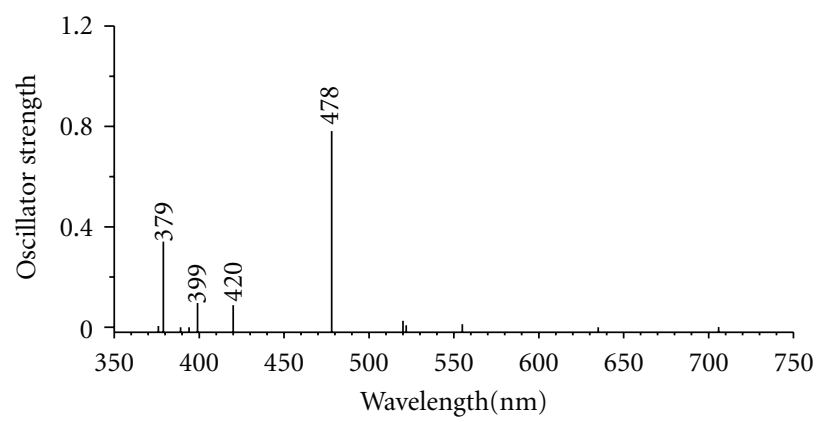

(e) PTP bearing $\mathrm{R}=-\mathrm{OH}$

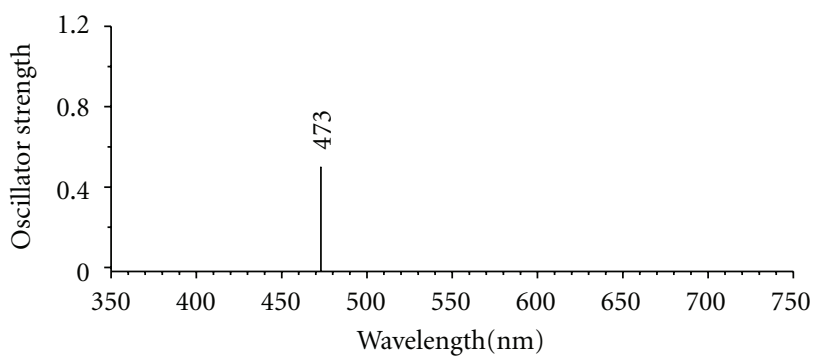

(b) Perylene

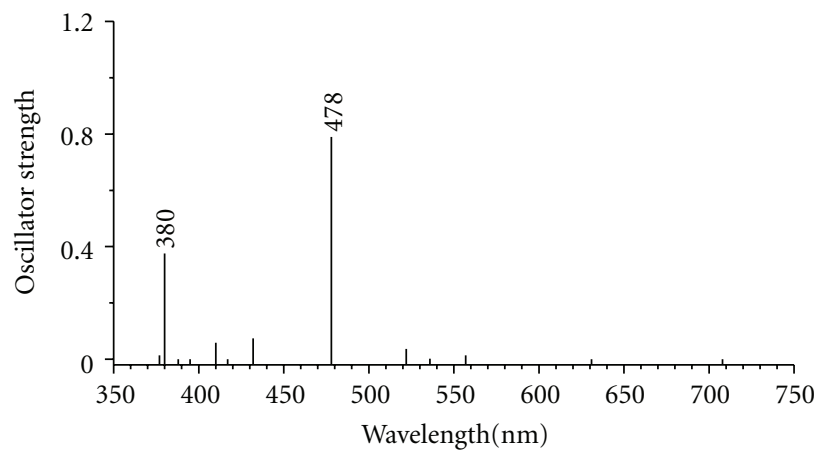

(d) PTP bearing $\mathrm{R}=-\mathrm{OCH}_{3}$

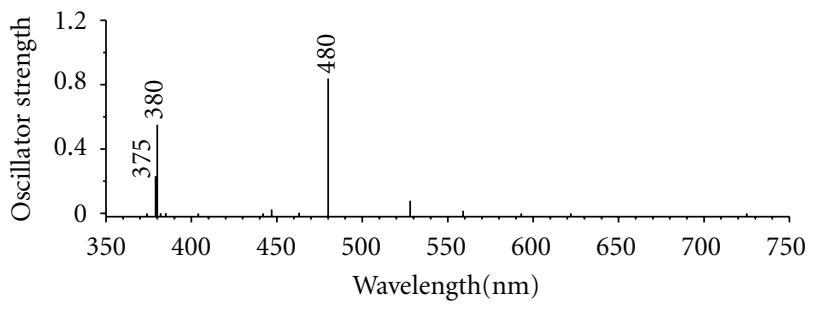

(f) PTP bearing $\mathrm{R}=-\mathrm{NH}_{2}$

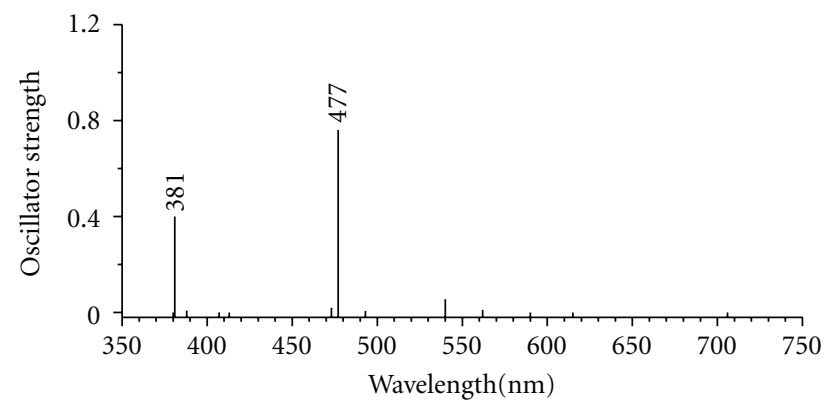

(g) PTP bearing $\mathrm{R}=-\mathrm{N}\left(\mathrm{CH}_{3}\right)_{2}$

FIgURE 6: UV-visible spectra of the free-base porphyrin, perylene, PTP compound $\left(\mathrm{R}=\mathrm{R}^{\prime}=-\mathrm{H}\right)$, and the four newly designed derivatives which provide a significantly lower energy gap, relative to those of the PTP compounds, (marked as bold characters in Table 2). 
and $473 \mathrm{~nm}$, remain essentially unchanged in peak height and show only a slight shift. The porphyrin peak shows only a slight shift to $380,379,380$, and $381 \mathrm{~nm}$ for the four derivatives, $\mathrm{R}=\mathrm{R}^{\prime}=-\mathrm{OCH}_{3},-\mathrm{H} ;-\mathrm{OH},-\mathrm{H} ;-\mathrm{H},-\mathrm{NH}_{2}$; and $-\mathrm{N}\left(\mathrm{CH}_{3}\right)_{2},-\mathrm{H}$, respectively. The corresponding values for the perylene peaks of those derivatives are 478, 478, 480, and $477 \mathrm{~nm}$.

\section{Conclusion}

This study focused on the investigation of the structural and electronic, as well as the optical, properties of a newly designed series of conjugated molecules bearing unsubstituted porphyrin and perylene moieties linked via a 2,5thiophenylene bridge (PTP). The thiophenylene bridge was assigned to be unsubstituted, monosubstituted, or symmetrically disubstituted at its $\beta$-position(s). The B3LYP/6-31G(d) level was found to be the calculation method of choice, serving as a compromise to attain a satisfactorily acceptable level of accuracy within tractable and realistic computational costs. By this method, the optimum torsion angle between the molecular planes of the lateral porphyrin or perylene unit and the central thiophene ring and the effect of substitution at the 3 and/or 4 positions of the thiophene ring were intensively investigated. The results showed that the existence of the substituents predominantly distorted the torsion angle between the perylene and thiophene molecular planes. Furthermore, energy gaps and HOMO-LUMO energy levels of the molecules were both electronically and sterically influenced by the types and position of the substituents. As regards excitation profiles, a shift of the molecular electron density from porphyrin to perylene moieties in the PTP compound was observed, indicating the possible excitedstate electronic communication in the molecule, which is a key mechanism in any light-harvesting system. Moreover, the predicted absorption of these compounds appeared to cover a range of $370-730 \mathrm{~nm}$, wherein the beneficial characteristic absorption of porphyrin and perylene remains intact. These results suggested that PTP and its substitution derivatives should be potential candidates for light-harvesting applications. Detailed studies are in progress and will be published elsewhere.

\section{Acknowledgments}

Financial support was provided by the MRG-WII collaboration with the 90th anniversary of Chulalongkorn University fund (Ratchadaphiseksomphot Endowment Fund), Project no. 515S045; the RTA Project no. 4980006 from the Thailand Research Fund; the Center of Excellence for Petroleum, Petrochemicals, and Advanced Materials, Chulalongkorn University. T. Chokbunpiam and O. Saengsawang thank the Commission on Higher Education for Sandwich Ph.D. Program (CHE-PHD-SW) and Postdoctoral Program (CHERES-PD), respectively. All facilities and computer resources were provided by the Computational Chemistry Unit Cell at Department of Chemistry, Faculty of Science, Chulalongkorn University.

\section{References}

[1] M. Gräzel, "Conversion of sunlight to electronic power by nanocrystalline dye-sensitzed solar cell," Journal of Photochemistry and Photobiology A, vol. 164, no. 1-3, pp. 33-14, 2004.

[2] S. Prathapan, S. I. Yang, J. Seth et al., "Synthesis and excitedstate photodynamics of perylene-porphyrin dyads. 1: parallel energy and charge transfer via a diphenylethyne linker," Journal of Physical Chemistry B, vol. 105, no. 34, pp. 82378248, 2001.

[3] M. P. O’Neil, M. P. Niemczyk, W. A. Svec, D. Gosztola, G. L. Gaines III, and M. R. Wasielewski, "Picosecond optical switching based on biphotonic excitation of an electron donor-acceptor-donor molecule," Science, vol. 257, no. 5066, pp. 63-65, 1992.

[4] A. C. Benniston, A. Harriman, D. J. Lawrie, and A. Mayeux, "The photophysical properties of a pyrene-thiopheneterpyridine conjugate and of its zinc(II) and ruthenium(II) complexes," Physical Chemistry Chemical Physics, vol. 6, no. 1, pp. 51-57, 2004.

[5] A. C. Benniston, A. Harriman, D. J. Lawrie, A. Mayeux, K. Rafferty, and O. D. Russell, "A general purpose reporter for cations: absorption, fluorescence and electrochemical sensing of zinc(II)," Dalton Transactions, no. 24, pp. 4762-4769, 2003.

[6] Y. Hoshino, T. Suzuki, and H. Umeda, "Amplification of metal-to-metal communication in the ruthenium (IV)-ruthenium(III) mixed-valence state of binuclear $\beta$ diketonatoruthenium complexes by inserting thiophene and anthracene units into acetylene linkers," Inorganica Chimica Acta, vol. 245, no. 1, pp. 87-90, 1996.

[7] Y. Okuno, T. Kamikado, S. Yokoyama, and S. Mashiko, "Theoretical study of aryl-ring rotation in arylporphyrins," Journal of Molecular Structure, vol. 594, no. 1-2, pp. 55-60, 2002.

[8] Y. Okuno, T. Kamikado, S. Yokoyama, and S. Mashiko, "Determining the conformation of a phenylene-linked porphyrin dimer by NMR spectroscopy and quantum chemical calculations," Journal of Molecular Structure, vol. 631, pp. 1320, 2003.

[9] J. C. Earles, K. C. Gordon, D. L. Officer, and P. Wagner, "A spectroscopic and computational study of the neutral and radical cation species of conjugated aryl-substituted 2,5bis(2-thien-2-ylethenyl)thiophene- based oligomers," Journal of Physical Chemistry A, vol. 111, no. 30, pp. 7171-7180, 2007.

[10] L. A. Estrada, V. A. Montes, G. Zyryanov, and P. Anzenbacher Jr., "Triplet energy studies of thiophene and para-phenylene based oligomers," Journal of Physical Chemistry B, vol. 111, no. 25, pp. 6983-6986, 2007.

[11] Y. Chen, Y. Lin, M. E. El-Khouly et al., "Supramolecular zinc phthalocyanine-perylene bisimide triad: synthesis and photophysical properties," Journal of Physical Chemistry C, vol. 111, no. 44, pp. 16096-16099, 2007.

[12] D. P. Hagberg, T. Edvinsson, T. Marinado, G. Boschloo, A. Hagfeldt, and L. Sun, "A novel organic chromophore for dyesensitized nanostructured solar cells," Chemical Communications, no. 21, pp. 2245-2247, 2006.

[13] I. D. Petsalakis, N. Tagmatarchis, and G. Theodorakopoulos, "Theoretical study of fulleropyrrolidines by density functional and time-dependent density functional theory," Journal of Physical Chemistry C, vol. 111, no. 38, pp. 14139-14149, 2007.

[14] X. Zhang, J.-J. Zhang, and Y.-Y. Xia, "Molecular design of coumarin dyes with high efficiency in dye-sensitized solar cells," Journal of Photochemistry and Photobiology A, vol. 194, no. 2-3, pp. 167-172, 2008. 
[15] M. J. Frisch, G. W. Trucks, H. B. Schlegel et al., Gaussian 03, Revision C.02, Gaussian, Inc., Wallingford, Conn, USA, 2004.

[16] M. Gouterman and D. Dolphin, The Porphyrins, vol. 3, Academic Press, NewYork, NY, USA, 1978.

[17] D. Sundholm, "Interpretation of the electronic absorption spectrum of free-base porphin using time-dependent densityfunctional theory," Physical Chemistry Chemical Physics, vol. 2, no. 10, pp. 2275-2281, 2000. 


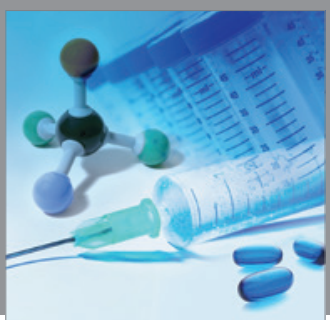

International Journal of

Medicinal Chemistry

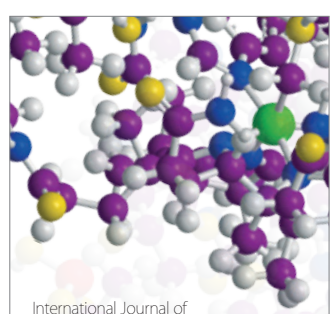

Carbohydrate Chemistry

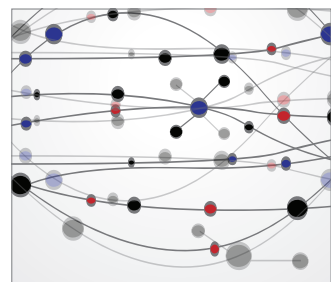

The Scientific World Journal
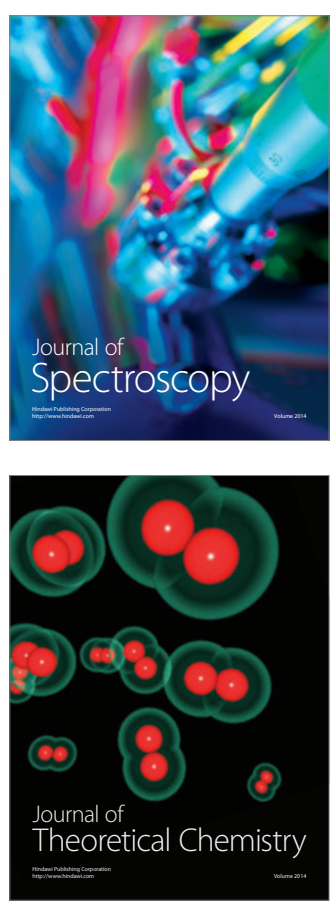
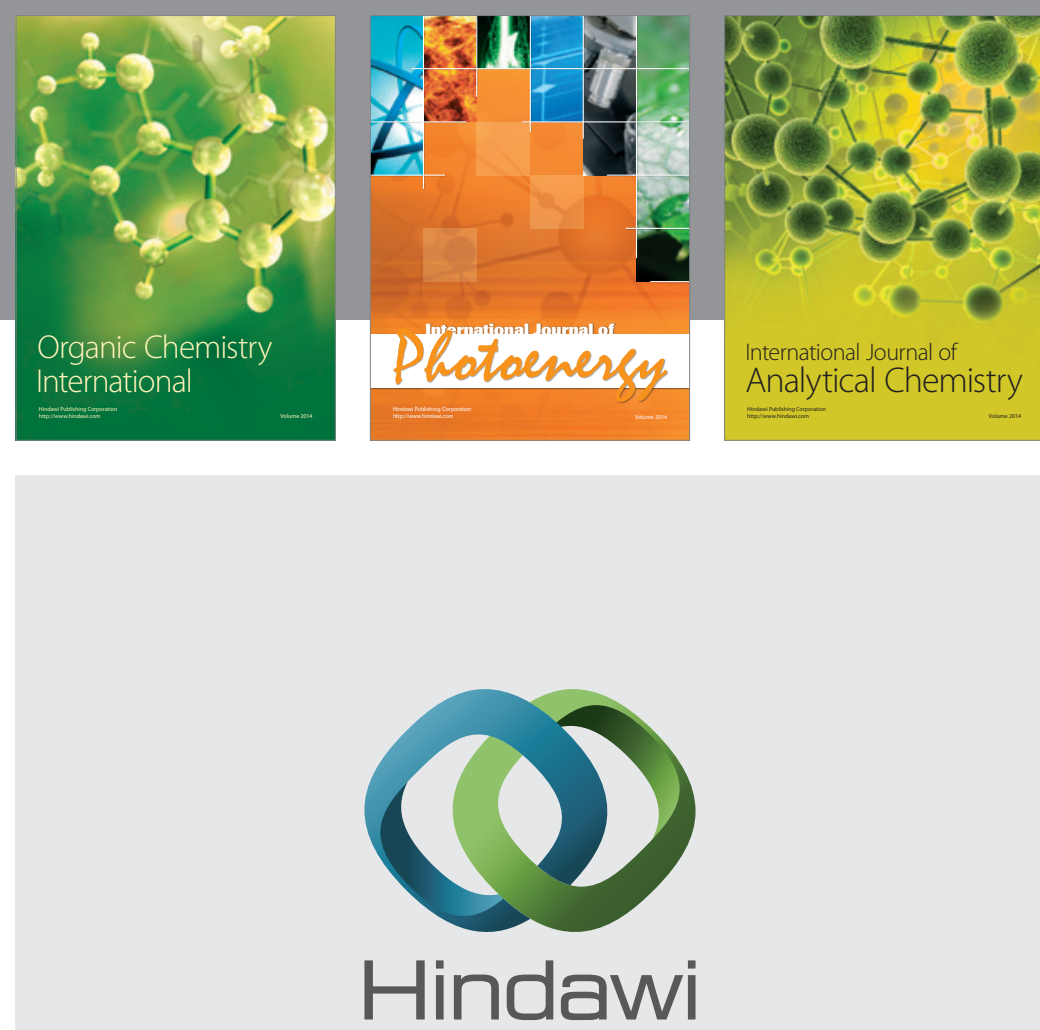

Submit your manuscripts at

http://www.hindawi.com
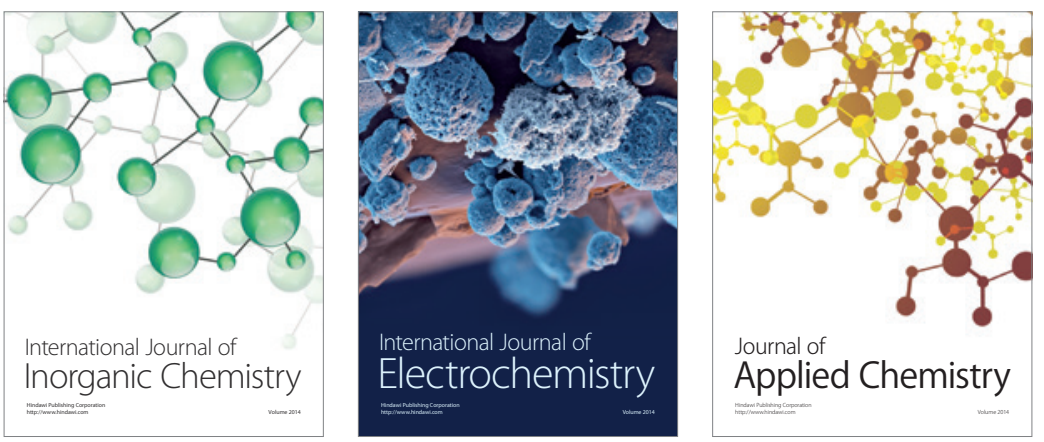

Journal of

Applied Chemistry
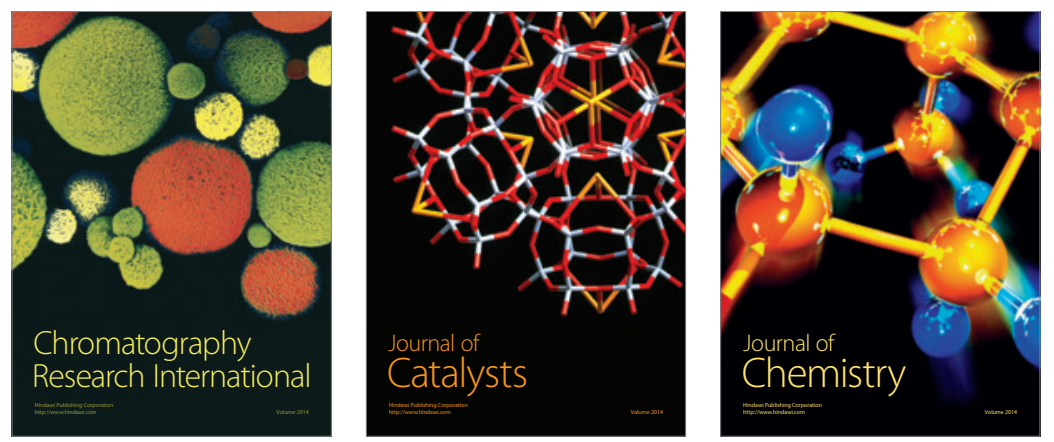
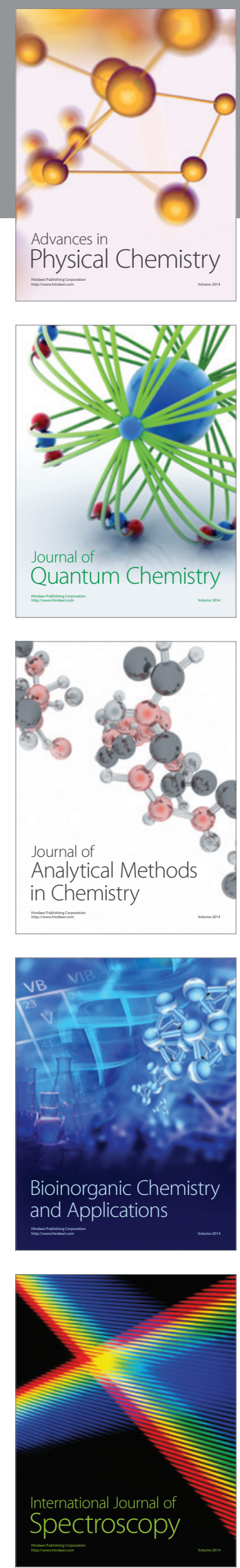